\title{
Pekka Hakamies: Arkistosta kentälle ja takaisin
}

\author{
Tuomas Hovi ja Antti Lindfors
}

\begin{abstract}
Dekka Hakamies jäi eläkkeelle folkloristiikan professorin paikalta Turun yliopistosta keväällä 2018. Hän piti läksiäisluentonsa 18. syyskuuta 2018. Haastattelimme häntä kuukausi läksiäisluennon jälkeen. Haastattelun kuluessa erinomaisen tarkkaa vuosilukujen ja tapahtumien muistamista osoittanut Pekka avasi meille vaiheikasta folkloristin uraansa, tutkimuksellisia preferenssejään ja paljasti myös joitain eläkesuunnitelmistaan.
\end{abstract}

\section{Sitä Kuusta kuuleminen...}

Ajatus akateemisesta uravaihtoehdosta tuli Pekalle jossain määrin verenperintönä: yliopisto-opintoja löytyi molempien vanhempien suvuista ja Pekan romanisti-isä oli näyttänyt esimerkkiä väitöskirjallaan "latinan kielen deminutiivin säilymisestä romaanisissa kielissä". Varsinaisesti lukioaikoina heränneelle kulttuurikiinnostukselle antoi virikkeitä isovanhemmilla selailtu I. K. Inhan Kalevalan laulumailla. Helsingin yliopisto oli syntyperäiselle pääkaupunkilaiselle ja "poika-Norssin" kasvatille luontevin ympäristö tyydyttää kasvavaa lukuintoaan.

Psykologian opintoihin tähdännyt Hakamies sai yliopistoon tullessaan pääaineekseen kakkosvaihtoehdon suomalaisen ja vertailevan kansanrunoudentutkimuksen. Alun perin sivuaineeksi ajateltu oppiaine jäikin pääaineeksi. Professori Matti Kuusen legendaarisena pidetty peruskurssi vuoden 1972 syksyllä käänsi hänen mielensä kauaskantoisin seurauksin. Helsinkiläistä kulttuuritieteiden opiskelua 1970-luvulla määritti suuressa määrin juuri Kuusen vaikutusvaltainen hahmo. Tämä muun muassa kutsui erinäisiä asiantuntijoita kansanrunoudentutkimuksen laitokselle opinnäytetöitä kommentoimaan aina proseminaaritutkielmista alkaen:

Anna-Leena Siikala muistaakseni kertoili aikanaan, että hän opiskelijana teki esitelmän, joka jollakin tavalla liittyi härkäkulttuuriin, ja kuinka ollakaan siellä istui sitten pöydän ääressä, niin... Kustaa Vilkuna, siinä vaiheessa jo akateemikko [naurua] joka kommentoi tätä työtä...

Jo kouluiässä alkanut kiinnostus Venäjän kieleen ja kirjallisuuteen johdatti Pekan hänen proseminaarityönsä aiheeseen. Työ koski samoihin aikoihin Suomessa vierailleen leningradilaisen Kirill V. Čistovin tutkijapersoonaa. 


\begin{abstract}
...vähän mua arvelutti, koska ei mun venäjän kielen taitoni mikään hirmuisen hyvä vielä siinä vaiheessa ollut. No sitten kun mietin että mitenkä tässä pääsis alkuun niin mä sain Kirill Čistovin postiosoitteen, joka oli tiedossa, ja sitten parhaan venäjän kielen taitoni pohjalta laadin hänelle kohteliaan kirjeen, jossa esittäydyin ja kerroin että opiskelen Matti Kuusen johtamassa seminaarissa ja ja.... mulle annettiin tämmönen seminaarityön aihe, ja olisin hyvin kiitollinen, jos professori Čistov voisi ystävällisesti kirjoittaa mulle jonkun verran... vähän kertoa itsestään ja töistään. No sitten meni jonkun aikaa niin mä sain postissa niin... parikymmentä koneella kirjoitettua venäjänkielistä sivua, jossa Čistov kertoo lyhyesti elämän kulkunsa ja työuransa ja esitteli tärkeimmät teoksensa. Ja kun mä menin sitä kirjettä näyttämään sitten Kansanrunoustieteen laitokselle niin Seppo Knuuttila, siinä vaiheessa vissiin jo assistentti, naurahti että "tuon kun suomennat niin siinähän sulla on valmis esitelmä!"
\end{abstract}

Valmistuttuaan maisteriksi vuonna 1981 Hakamies rekrytoitiin määräaikaiseksi tutkijaksi Suomalaisen Kirjallisuuden Seuran Kansanrunousarkistoon, josta hän oli jo aiemmin harjoittelijana löytänyt gradunsa aiheen. Arkistossa oli nimittäin käynnissä sananparsikortiston järjestelyprojekti, jota edistettiin "välillä SKS:n rahoilla, välillä ilmeisesti Matti Kuusen omilla rahoilla". Projektiin osallistuessaan Hakamies saattoi tutustua itsekin aineistoon. Varsinaisen väitöskirjatutkimuksensa Hakamies aloitti siirryttyään Helsingin yliopiston kansanrunoustieteen laitokselle viransijaiseksi määräaikaiseksi assistentiksi lyhyen Kansanrunousarkistokeikan jälkeen. Väitöskirjassa hän syvensi gradussa aloittamaansa teemaa - venäläisten sananparsien vaikutusta karjalaiseen ja suomalaiseen sananparsistoon.

Tiivis yhteys Helsingin yliopistoon ja Kansanrunousarkistoon katkesi vasta kun silloisen Joensuun korkeakoulun Karjalan tutkimuslaitokseen perustettiin amanuenssin virka, jonka hyvässä vauhdissa ollut väitöskirjatutkija sai. Pekan puheista ja hänen uraputkensa saumattomista siirtymistä välittyykin nykyiseen nähden toisenlainen työilmapiiri, jossa vähempilukuisella opiskelijajoukolla oli sitäkin luottavaisemmat työllistymisnäkymät:

Silloin oli toinen maailma, että... kyllä se oli monessa suhteessa helpompi kuin tää nykyinen. [...] Joskus [amanuenssi] Jöns [Carlsonilta] kysyin, että minkäslaisia työmahdollisuuksia on sitten kun valmistuu. Niin Jöns sanoi jotenki sillä tavalla puolihuolimattomasti että "silloin kun joku sattuu valmistumaan niin kyllä sille joku homma jostain keksitään" [naurua] Että silloin ei niin kun ollut sellaisia tulospaineita yliopistolla kuin nykyään.

\title{
Kenttätöiden merkitys folkloristiikassa
}

Pekka on uransa aikana tehnyt paljon kenttätöitä etenkin Pohjois-Karjalassa ja entisen Neuvostoliiton alueella ja tätä kautta kokenut myös suurvallan asteittaisen avautumisen länsimaiden suuntaan. Neuvostoliiton aikaan esimerkiksi Tartossa käyminen oli hankalampaa. Neuvottelumatkaa, jonka hän teki sinne Kari Laukkasen kanssa, Pekka muistelee lämmöllä. Matkoilla suunniteltiin muun muassa jatkoa Proverbia septentrionalialle, jonka ensimmäinen osa oli ilmestynyt FFC-sarjassa vuonna 1985:

Tartossa kun oli kaikki kansanrunouskokoelmat, Kansanrunousarkisto, niin kun suomalaiset tutkijat halusivat käyttää sitä aineistoa, niin he majoittuivat hotelliin Tallinnaan, ja sitten aamulla tuli Tiedeakatemian auto, otti heidät kyytiin ja ajoi sitten Tarttoon kolme tuntia, ja siellä tehtiin töitä kunnes arkisto meni kiinni joskus illansuussa, ja sitten sama auto toi iltaa myöten takaisin Tallinnaan. Että se oli neuvostomeininkiä, mutta sitten tosiaan '87 saatiin jo yöpyä Tartossa siitä huolimatta että sotilaslentokenttä oli siinä lähettyvillä.

Mieleenpainuvimpia kenttätyöreissuja ovat olleet vuonna 1993 Anna-Leena Siikalan johdolla tehty kenttätyöretki Udmurtiaan ja vuonna 1994 tehty retki Vieljärven kylään Aunuksen 
Karjalaan, jonne Pekka palasi myös vuosina 1996 ja 1998. Jälkimmäisten kenttätyöreissujen tutkimusaiheena Pekalla oli modernisoituminen Neuvosto-Karjalassa. Erityisesti häntä kiinnostivat alueella tapahtuneet muutokset.

...mulla oli sitten aiheena modernisoituminen Neuvosto-Karjalassa jolloinka mua kiinnosti se millä tavalla kulttuuri ja perinne oli muuttunut sitten sen jälkeen kun Neuvostovalta tuli voimaan ja maatilojen kollektivisointi ja kaikki tämmöset rakenteelliset jyrkät muutokset mitä siellä on tehty, niin mitenkä ne vaikutti perinteen elämismahdollisuuksiin. Mitenkä ne muuttivat kulttuuria ja itse tapaa elää.

Haastattelujen aikana tuli vastaan myös melko rankkoja elämänkokemuksia sekä tiettyä epäluuloisuutta haastattelijaa kohtaan.

...ja no siinä niissä haastatteluissa tuli kaiken näköistä järkyttävääkin esille, et oli tällainen silloin jo varsin vanha nainen joka asui sen kylän keskustassa vanhassa karjalaistalossa ja hän oli nuorena naisena työskennellyt kyläneuvoston sihteerinä muistaakseni 30-luvun lopussa ja hän moneen kertaan spontaanisti niin kun vaan totesi että, että kun kerta toisensa jälkeen koottiin semmoinen mieskulkue siihen niin kuin kyläneuvoston talon viereen ja niitä lähdettiin viemään ja kukaan niistä ei tullut takaisin. Joku kertoi isästään, että ilmeisesti kollektivisoinnin vaiheessa niin kolmesta sanasta hän oli saanut kolme vuotta karkotusta [...]. Tosin se nyt oli vielä sen verran lempeää aikaa, että se oli se kolme vuotta ja sitten hän pääsi takaisin sinne kylään mutta jonkinnäköistä esimakua tulevasta.

... hän niin kuin näytti että paneppa kiinni se nauhuri ja sen jälkeen sitten että mihinkäs näitä tietoja oikein kerätään, että kenenkäs korviin nämä menee, että vielä niin kuin muutama vuosi sitten niin tämmöisistä kysymyksistä olisi päässyt ristikon taakse ja, jollonka minä sitten koitin vakuuttaa että nämä menee minun omaan tutkimuskäyttööni että näille ei ole mitään muuta tarkoitusta, nämä ei mene kenenkään muun kuultavaksi, no sitten päästiin jatkamaan sitä keskustelua mutta, että vaikka siinä oli eletty jo kymmenkunta vuotta tämmöistä vapautumisen aikaa ja 90-luku oli demokratian aikaa, niin tuota kyllä aika syvällä korvien välissä tai selkäytimessä oli vielä tämä varovaisuus.

Pekka korostaa kenttätöiden merkitystä folkloristisessa tutkimuksessa, vaikka itse teki väitöskirjansa arkistoaineistosta. Hakamiehen mukaan hänen aloittaessaan opiskelut vallalla oli selkeähkö jako arkistotutkijoihin ja kenttätyötä tekeviin tutkijoihin.

Joo, no kyllä minun mielestä jokaisella folkloristilla pitäisi olla jonkun näköinen kokemus kenttätöistä koska se niin kuin avaa silmiä, sillä että millä tavalla arkistoon tulee aineisto. Outi Lehtipuro minulle aikanaan vihjaisi sellaisesta Martti Haavion artikkelista josta hän toteaa että, jokainen tutkimus alkaa arkistosta. No, Haavio on tietysti väärässä siinä, että kyllä se aineisto on ensin tullut sinne arkistoon niin sanotusti kentältä. Ja että sillä on jonkunnäköinen suhde siihen mitä ihmiset ovat tuolla maailman turuilla ja toreilla niin ja kotonaan niin kertoilleet ja laulaneet ja miettineet.

Kyllä se varmasti painottui jompaankumpaan, aineistosta ja kiinnostuksesta riippuen ja Matti Kuusihan oli aloittanut tämän populaarikulttuurin, poploren tutkimisen ja käynnistellyt sitä ja siinä vaiheessa niin, Jöns Carlson joskus näytti jossakin hyllyllä tämmöistä teosriviä että tuossa on populaarikulttuurin maailmaninstituutin kirjasto että se oli niin tuore asia silloin ja sellainen jota nimenomaan Helsingin yliopiston folkloristiikassa tehtiin, et silloin yks ja toinen teki sitten työnsä tämmöisestä populaarikulttuuriaiheesta, kyllä se minuakin sitten jollakin tavalla kiinnosti, koska se oli tämmöistä niin kun elävää ajassa kiinni olevaa, mutta sitten ehkä sen takia kun menin sinne arkistoon töihin ja jotenkin innostuin kaikesta siitä mitä siellä oli, niin antauduin sitten tämmöiseen arkistotutkimukseen siinä väitöskirjassani. 


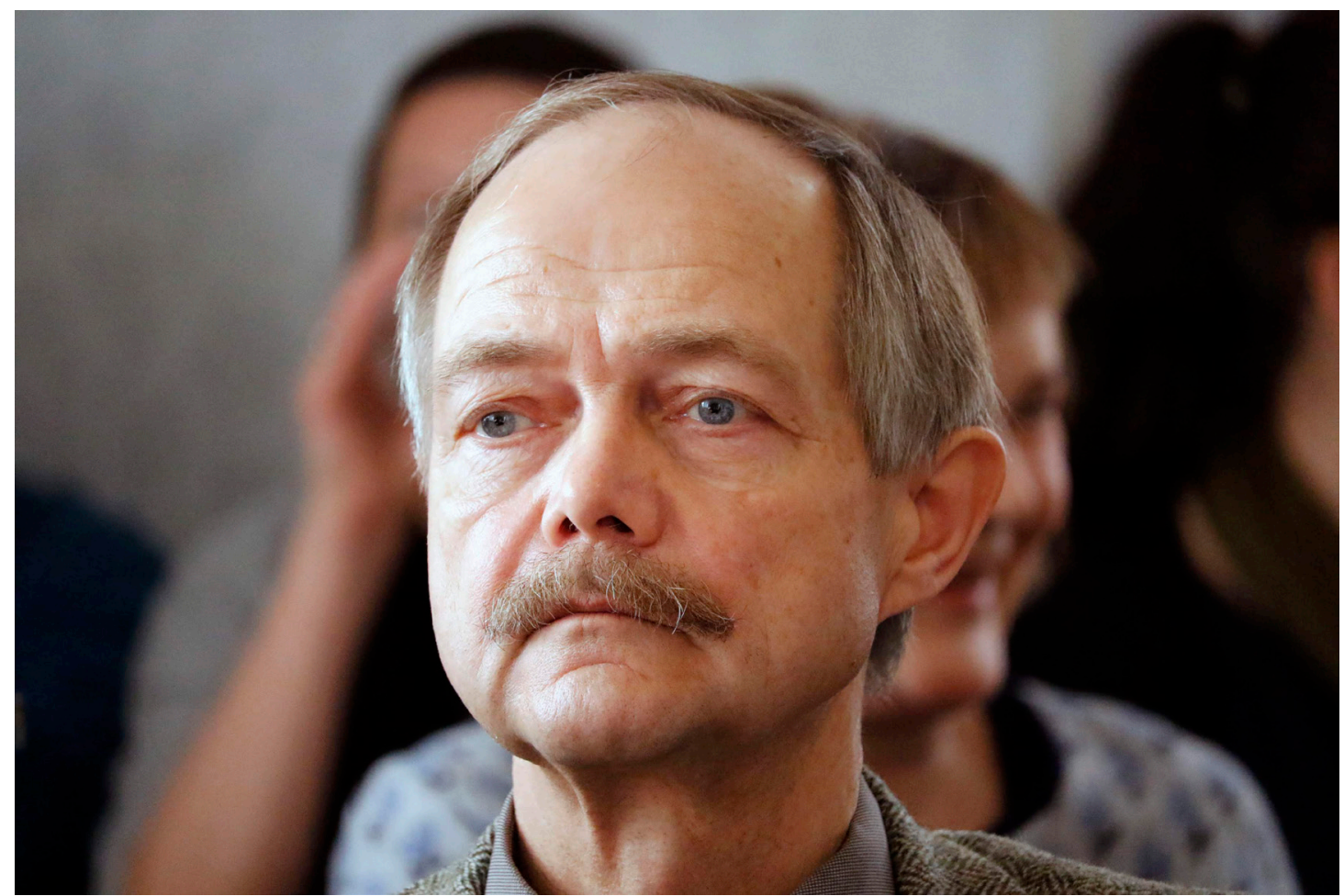

Prof. emer. Pekka Hakamies. Kuva: Ilkka Jukarainen. Kalevalaseura 2019.

\section{Seurat ja järjestöt}

Pekka on uransa aikana toiminut myös lukuisissa tieteellisissä järjestöissä ja seuroissa, ja hän näkeekin niissä toimimisen tärkeänä osana alan työkulttuuria. Opiskeluaikana Pekka toimi ainejärjestössä sekä rahastonhoitajana Suomen antropologisessa seurassa, tosin omien sanojensa mukaan hän ei jälkimmäisessä toimessa ollut kuitenkaan "hirmuisen menestyksellinen". Opiskeluaikojen jälkeen Pekka on toiminut puheenjohtajana Suomen Kansantietoudentutkijain Seurassa, Kalevalaseurassa, Joensuun yliopiston assistenttien ja tutkijain yhdistyksessä ja jäsenenä valtakunnallisessa assistenttiliiton hallituksessa, Suomalaisen Kirjallisuuden Seuran valtuuskunnassa ja hallituksessa, Folklore Fellows -verkoston työvaliokunnan puheenjohtajana, Studia Fennica Folkloristican toimittajana sekä FFC:n päätoimittajana.

\section{Helsingistä Joensuun kautta Turkuun}

Pekka on työskennellyt folkloristiikan parissa Helsingin, Joensuun ja Turun yliopistoissa. Pisimmän työuran Pekka kuitenkin teki Joensuussa sijaitsevassa Karjalan tutkimuslaitoksessa, jossa hän työskenteli vuodesta 1984 vuoteen 2006. Tuona aikana Pekka tosin hoiti myös erilaisia sijaisuuksia, kuten perinteentutkimuksen professuuria Joensuun yliopistossa 1987 ja 1995-1996 ja folkloristiikan professuuria Helsingissä 2000-luvun alussa. Turkuun Pekka tuli vuonna 2006, jolloin hänet valittiin folkloristiikan professoriksi. Turussa Pekka toimi professuurin ohessa muun muassa laitosjohtajana ensin pienemmässä Kulttuurien tutkimuksen laitoksessa ja myöhemmin laitosten yhdistyessä huomattavasti suuremmassa Historian, kulttuurin ja taiteiden laitoksessa. Pekka toimi myös humanistisen tiedekunnan varadekaanina. 
Pekalla on siis ainutlaatuinen näkökulma eri yliopistojen folkloristiikan oppiaineisiin Suomessa. Vaikka hän näkeekin eroja eri yliopistojen folkloristiikan tai perinteentutkimuksen oppiaineiden välillä, erot ovat pienissä oppiaineissa Hakamiehen mukaan hyvin pitkälti henkilösidonnaisia. Etenkin professorien omat mielenkiinnot ja lähestymistavat folkloristiikkaan tieteenalana ovat vaikuttaneet hänen nähdäkseen oppiaineiden profiliiin.

Eläkesuunnitelmissa Pekalla on paremiologian eli sananlaskututkimuksen jatkaminen sekä luovutetun Karjalan alueella 2000-luvun alussa tekemiensä kenttätyöhaastatteluiden läpikäyminen ja niiden pohjalta jonkinlaisen teoksen kirjoittaminen.

Elore kiittää Pekkaa myös hänen Eloren hyväksi tekemästään työstä ja toivottaa innoitusta eläkepäiville!

Filosofian tohtorit Tuomas Hovi ja Antti Lindfors ovat Pekka Hakamiehen oppilaita ja kollegoita Turun yliopistosta. 